\title{
Reinterpretación del trazado de la coracha zirí de Granada a la luz de los nuevos datos arqueológicos
}

Reinterpreting the layout of Granada's ziri coracha in the light of new archaeological data

\author{
Antonio Reyes Martínez a ${ }^{\text {Encarnación Reyes Martínez }}{ }^{\text {b }}$ \\ a Archaeologist, Granada, Spain, antoniodelosreyes@ hotmail.com \\ b Archaeologist, Granada, Spain, encarnireyes@ugr.es
}

\begin{abstract}
This article talks about the archeological intervention carried out in Concepción de Zafra street $\mathrm{n}^{\circ} 3$ in Granada, close to the Darro river. The house uses the perimeter eastern wall of the nasrid Maristan. Under this wall another tapial wall was discovered and possibly belongs to the coracha of the eleventh century.
\end{abstract}

Keywords: Granada, nasrid Maristan, eleventh century, coracha, tapial.

\section{Introducción}

El estudio de las murallas de Granada es un tema de constante actualidad por el continuo descubrimiento de nuevos tramos gracias al intenso ritmo de la arqueología urbana de las últimas décadas, que está ayudando a completar el plano hipotético que en su día presentó Luis Seco de Lucena (Seco de Lucena, 1910) y que actualizó Antonio Orihuela Uzal (Orihuela, 2002).

En cuanto a la coracha, ideada para el aprovisionamiento de agua procedente del rio Darro para el abastecimiento tanto de la Alhambra como de la alcazaba Qadima, para este segundo recinto defensivo, tradicionalmente se ha señalado que discurría por la calle Bañuelo. Sin embargo, durante la excavación arqueológica realizada en el $n^{\circ} 3$ de la calle Concepción de Zafra, hemos podido documentar un tramo de muralla, amortizado por el edificio del Maristán, que puede corresponder a la citada coracha o a algún elemento defensivo relacionado con ella. Esta hipótesis se apoya, a su vez, en las intervenciones arqueológicas llevadas a cabo en el hospital nazarí, donde se documentó la otra cara de esta misma muralla.
El término coracha fue definido por Torres Balbás como el espolón de muralla que, arrancando de la general del recinto, avanzaba para proteger una puerta o aislar una zona inmediata, casi siempre a un rio, y facilitar el acceso a este, el aprovisionamiento de agua en caso de asedio, a los defensores del recinto murado (Torres Balbás, 1941, p. 190). La coracha forma parte del entramado defensivo de la ciudad y es clave para el acceso a un elemento vital como es el agua, en el caso que nos ocupa, del rio Darro.

\section{Contexto histórico y arqueológico}

El solar intervenido se encuentra en la ladera sur del Albaicín en el barrio de San Pedro o barrio de Axares, quedando la mencionada calle Concepción de Zafra enmarcada entre la Carrera del Darro al sur y Portería de la Concepción al norte. El inmueble se sitúa lindando con el solar que ocupa el antiguo Maristán nazarí al oeste, al norte con el $n^{\circ} 1$ de la calle Concepción de Zafra y al sur con el $n^{\circ} 5$. Al otro lado de la calle, frente al inmueble objeto de la intervención se encuentran la Casa Nazarí de Zafra y el Convento de Santa Catalina de Zafra, ambos al este. 
También en las proximidades del inmueble intervenido se sitúan los baños árabes del Nogal o Bañuelo, así como los restos de la Bāb alDifāf (Fig. 1), ya en el Darro, en definitiva, un reducido espacio donde se concentran un gran número de monumentos, imprescindibles para el conocimiento de la Granada islámica a nivel histórico y arqueológico.

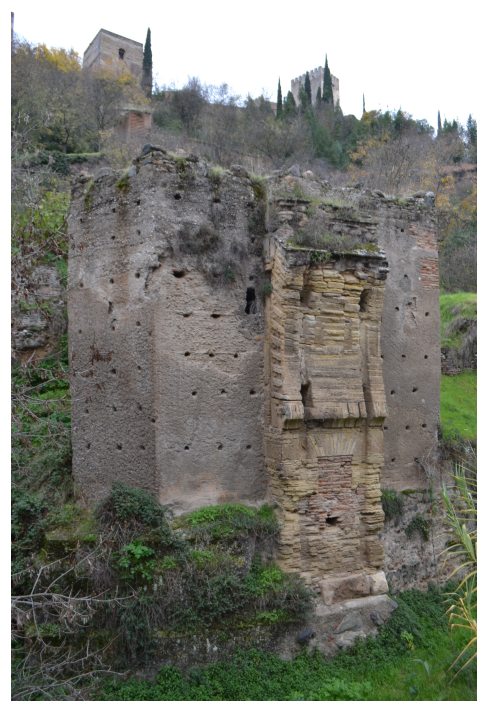

Fig. 1. Bāb al-Difāf.

El primer núcleo existente en Granada no debió de ocupar más que la zona que abarcaba el antiguo oppidum ibero-romano, y se extendía entre la plaza de San Miguel Bajo y el mirador de San Nicolás, que eran aproximadamente de 9-10 hectáreas en el siglo VI a. C. (Adroher, et al., 2002, p. 83). Nos hallamos, pues, ante un emplazamiento con pasado romano, pero cuya monumentalidad debió de ser prácticamente inexistente en el momento en el que se produce la ocupación arabo-islámica, como lo demuestra la ausencia de grandes hallazgos relativos al mundo romano, así como la inexistencia en las fuentes de menciones a ruinas o a un pasado de la ciudad romana.

La primera referencia sobre la Granada islámica corresponde al momento de la ocupación, que debió de ser en torno al 712. En el siglo VIII se mantendría un hábitat disperso en torno a un hiṣn localizado sobre un asentamiento ubicado en el Albaicín.

Posteriormente, en la etapa de luchas de la primera Fitna, a finales del siglo IX, este hiș̣n iría adquiriendo una mayor importancia, lo que se ve reflejado en su protagonismo, como centro en el que se atrincheran Sawwār y los árabes (Gómez Moreno, 1905, p. 52). Todo parece indicar que se produjo en estos momentos una oleada de inmigración de población, principalmente árabe, que permanecería en el hiṣn y que producirá un cambio importante en la entidad que representará Granada desde entonces. Los primeros pasos en la fundación de esta madina se darían con Zāwī b. Zīrī hacia el 1013 e irían encaminados a la construcción de la alcazaba antigua y de las primeras viviendas en torno a ésta.

El recinto fortificado de la Granada Zirí se desarrolla partiendo de los restos de la Alhacaba, sita entre el arco de las Pesas y la puerta de Monaita, la muralla continuaría en ascenso hacia el carril de San Cecilio enlazando con la Bāb Qaštar también denominada Ḥiṣn Ruman. Desde Bāb Qaštar sigue hacia el torreón situado en el Centro de Salud Albaycín, pasaba por la calle Espaldas de San Nicolás y tras ésta por el carril de las Tomasas. Junto al convento de las Tomasas habría otra torre desde la que partiría un paño de muralla, que iría hacia el sur pasando por el Carmen Aben Humeya, para enlazar con otro torreón sito en la calle Guinea. De aquí, se dirigiría a la placeta de las Escuelas, donde aún queda otra torre relativamente bien conservada. Tras esto, continuaría hacia occidente, por el interior de las viviendas de números impares de San Juan de los Reyes. Todo esto constituiría el sector sureste y el más próximo al Darro donde estaba la coracha para tomar agua del río. En esta zona la muralla está oculta por las viviendas que, como práctica común, la aprovechan adosándose a ella. Por lo tanto, la cerca zirí discurriría por toda la calle San Juan de los Reyes hacia el oeste, pasando por el jardín de la vivienda localizada en el $n^{\circ}$ 15 de San Juan de los Reyes, por el $\mathrm{n}^{\circ} 7$ y por la placeta de las Porras. Desde aquí se dirigiría, por la calle Beso y la cuesta de las Arremangadas, cruzando la cuesta de San Gregorio, hasta 
carril de la Lona para finalmente engarzar con la puerta de Monaita (Sarr, 2007, p. 171).

Con la construcción de la mezquita mayor, en la parte baja de la medina, el sistema defensivo ha de ampliarse. En este contexto, se levantaría el tramo comprendido entre puerta de Monaita y Elvira. Aquí, en la placeta del Boquerón, estaría la puerta de las Cuatro Fuentes. Otro tramo iría hasta el convento de la Encarnación. Posteriormente los muros de la cerca continuarían hasta la Iglesia de Justo y Pastor, junto a la que estaría la Puerta del Molino, después llamada puerta de San Jerónimo, lo que nos indica que estaba situada en la actual calle homónima. Desde aquí continuaría rodeando la antigua mezquita mayor y enlazaría con Torres Bermejas cerrando el sistema defensivo en este punto (Sarr, 2011, pp. 141, 148).

La coracha unía la alcazaba Qadima en el Albaicín con la alcazaba de la Alhambra. El tramo que baja desde la Alhambra hasta el Darro parece que fue mandado a construir por Abd Allāh (1077-1090) al igual que la Bāb al-Difāf (Vílchez, 2012, p. 135). Mientras levantaba esta muralla halló un tesoro enterrado con 3000 monedas de oro, según refiere en sus Memorias:

"He aquí lo ocurrido: Cuando ordené la construcción del muro contiguo a la Alhambra [...], tuvimos la buena fortuna de que los albañiles encontraron, al hacer los cimientos, una orza llena de oro. Avisado de la noticia, hallé en dicha orza tres mil meticales ŷa faríes; cosa que me regocijó y que me pareció de buen agüero para la realización de mis empresas (¡así se burla de nosotros el mundo, como antes se burló de nuestros ascendientes!). "De los cimientos va a salir la construcción", me dije". (García Gómez, Leví-Provençal, 1981, pp. 237238.)

En el siglo XII, Al-Zuhrī habla de la manera en que quedaban unidas las dos alcazabas a través de la coracha:

"El río entra en Granada por el norte y sale por el sur entre las dos alcazabas, junto a una compuerta fortificada, de elevada construcción. En esta compuerta se habían colgado batientes blindados con placas de hierro y se construyeron murallas desde la alcazaba pequeña hasta la grande. En dicha compuerta fueron abiertas dos pequeñas puertas para poder aprovisionarse de agua en tiempos de guerra. [Esta compuerta] no tiene parangón en al-Andalus" (Al-Zuhrī, 1991, p. 170; Sarr, 2011, p. 168).

Seco de Lucena la describe de la siguiente manera:

"La qawraya castrense debía cubrir el camino que desde el extremo meridional de dicho primitivo recinto más cercano a la ribera del Darro conducía hasta este río; y no estimo muy aventurado suponer, con bastantes probabilidades de acierto, que el citado espolón arrancaba desde muy cerca del lugar en que media la calle Aljibe del Trillo descendiendo hasta él y descendía hasta el río casi en línea perpendicular al cruce del mismo, hasta el torreón que hubo en su margen derecha, al final de la calle del Bañuelo, torreón que más tarde, al ser construida Bab al-Difaf, o Puerta de los Tableros vulgarmente llamada Puente del Cadí, sirvió de flanco Norte a dicha puerta" (Seco de Lucena, 1968, pp. 197-203, 198-200).

Del mimo autor tenemos lo siguiente sobre el llamado barrio de la coracha en el entorno del Maristán:

"Siguiendo hácia Levante, también circumbalado por los muros de la Alcazaba Gidida, al N. de la mezquita de los Convertidos, actual iglesia de San Juan de los Reyes, extendíase el Barrio de la Cauracha por las cuestas del Algibe Grande, del Almez y del Algibe de Trillo y las veredas y callejones de San Agustín. Dicen que este barrio tomó su nombre de una cueva (caara) que en él existía" (Seco de Lucena, 1975, pp. 26-27).

La Bāb al-Difāf la repara Leopoldo Torres Balbás entre 1932 y 1934, habiendo comprado antes la finca donde estaba a la Compañía de Tranvías Eléctricos, S.A. el 4 de septiembre de 1932, (Vílchez, 2012, p. 135).

La coracha o muralla es representada en la Plataforma de Ambrosio de Vico (1590-1610) pero ya no aparece en el Mapa Topográfico de 
Dalmau realizado en 1796 (Vílchez, 2012, p. 135).

Esta muralla la excavó en la década de 1960 Jesús Bermúdez Pareja, y se reconstruyó en ladrillo guardando los restos antiguos. Este fragmento de muralla tiene dos torres que miran al este:

"Del tramo de muralla de la cerca general de Granada entre la Alcazaba de la Alhambra y la Alcazaba Vieja [..], no quedaba más testimonio a la visita que las ruinas de la Puerta de los Tableros o Bab al-Difaf, que ha venido confundiéndose con el Puente del Cadí, que estuvo más abajo, junto a la iglesia de Santa Ana. Desde las ruinas del torreón que subsiste, surge hacia la Alhambra, perpendicular a la ladera, un tramo de muralla que hace unos años se limpió y consolidó, sin recrecerle. Luego el monte se escarpa con violencia y el muro se pierde entre obras de contención rehechas en varias épocas. Más arriba quedaban confusos testimonios al parecer de un torreón. Dentro del plan general de consolidación de murallas de la Alhambra, se acometió la limpieza de aquellos restos que han permitido encontrar dos torreones más y los lienzos de cortina de la muralla que entre ellos suben hacia la Torre de las Armas estableciendo el límite entre la ciudad y el campo, en esta ladera de la Alhambra" (Bermúdez, 1966, pp. 139-140).

\section{Resultados de la intervención arqueológica}

\subsection{Análisis del muro del Maristán desde el punto de vista de la estratigrafía muraria}

La primera parte de la intervención arqueológica se centró en el análisis de paramentos a través de una serie de catas que se realizaron en diferentes puntos de la vivienda, aunque con especial atención a su muro trasero, tras descubrir que la vivienda carecía de muro perimetral propio y que ésta se adosaba directamente al edificio del Maristán.

Dicho muro presenta una anchura de $65 \mathrm{~cm}$ y está cubierto por entre 5 y 7 capas de pinturas modernas y morteros, la mayoría de ellos obedecen a sucesivas reparaciones, dado que se trata de una construcción afectada por las humedades, especialmente en su parte inferior.

Estas reparaciones van disminuyendo conforme ascendemos de cota. En la parte inferior del muro hemos documentado sucesivas cajas de mampostería alternadas con doble encintado de ladrillos dispuestos a tizón, las cuales obedecen posiblemente a reparaciones del tapial. Sobre estas cajas continúa la obra de tapial propiamente dicha en la que podemos distinguir, en primer lugar, un tapial marrón, con escasa cal, sobre el que descansa un tapial muy rojizo y sobre este un tapial calicostrado de muy buena calidad.

Desde el punto de vista constructivo presenta características similares a las de los otros muros perimetrales de este hospital nazarí, mampostería encintada con dos hileras de ladrillos en la zona más baja y sobre esta, tapial, del que diferenciamos un tapial gris situado sobre la mampostería encintada y un tapial rojizo situado sobre el tapial gris. Muhammad V reaprovecharía un edificio anterior al hospital nazarí y sobre él levantó un edificio nuevo con parte del precedente, lo que explicaría los dos tipos de tapial que podemos ver en los muros perimetrales (gris y rojo) y la rapidez en la construcción del hospital nazarí, 20 meses (García Granados, 1989, p. 27).

En la cata realizada en la primera planta de la vivienda encontramos los huecos tapados de un antiguo forjado cuya función se nos escapa, sin poder determinar si se trata de un antiguo nivel de planta de la casa o si por el contrario puede tratarse de la cubierta de las posibles tiendas de época nazarí que suelen estar ubicadas junto a edificios públicos de este tipo. Esta circunstancia explicaría además la planta rectangular que presenta esta casa.

\subsection{Estructuras anteriores al Maristán Na- zarí. Descripción e interpretación}

Una vez realizado el análisis de estructuras emergentes se realizó la intervención arqueológica en el subsuelo de la planta baja de la vivienda.

Tras excavar los estratos contemporáneos y modernos, en los que pudimos exhumar varios 
niveles de suelos de baldosas y pavimentos empedrados, empezamos a exhumar las estructuras correspondientes al periodo andalusí.

El elemento arquitectónico de mayor relevancia documentado es un muro que discurre en dirección noroeste-sudeste, de diez metros de longitud, una anchura mínima de $1,10 \mathrm{~m}$ y una potencia de $2 \mathrm{~m}$. En dicha altura se desarrollan casi tres cajones de tapial de cal y canto, dos completos y el más superficial, parcialmente arrasado, conserva algunas de las improntas de las tablas de madera con la que fue levantado (Fig. 2).

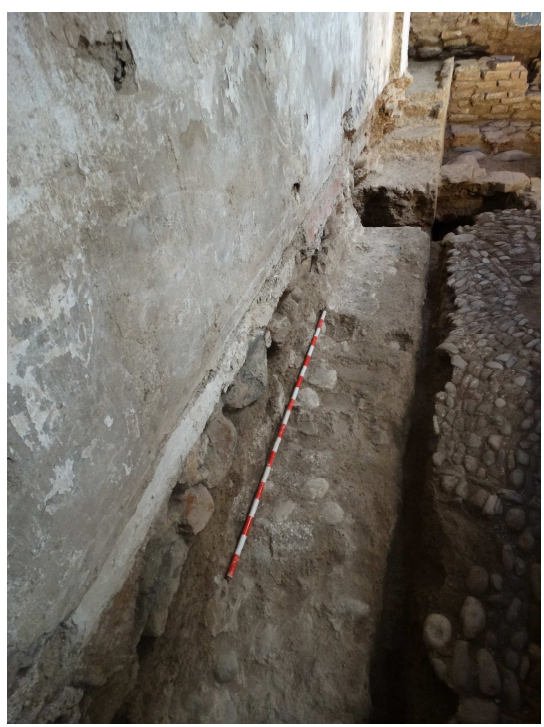

Fig. 2 Muralla identificada con la coracha sobre la que se apoya parcialmente el muro perimetral este del Maristán.

La caja documentada a la cota más baja presenta un pequeño retranqueo respecto al resto de la construcción, esta circunstancia puede deberse a que nos encontramos ya a nivel de cimentación. Aunque no pudimos excavar más parece que la tapia arranca en este punto, aunque también puede que estemos ante una rotura.

Desde el punto de vista estratigráfico hay que señalar que el muro perimetral este del Maristán apoya parcialmente sobre el muro descrito, por tanto, nos encontramos con una construcción anterior al hospital nazarí, por lo que apuntamos como hipótesis su identificación con un tramo de la muralla de la coracha.

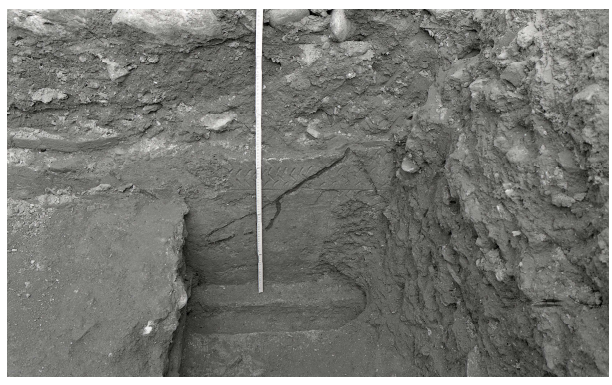

Fig. 3 Muro documentado en las excavaciones del Maristán identificado con la coracha. (Foto: Juan Antonio García Granados).

La cerámica documentada en el interior del muro de la coracha, en la caja de tapial más superficial, aunque minoritaria, es lo suficientemente representativa para fijar una cronología que estaría en torno al siglo XI. Los fragmentos recuperados y que nos han servido de fósil director son ataifores vidriados melados y con decoración en cuerda seca de pies escasamente desarrollados y cerámica de cocina sin vidriar. Los estratos más antiguos, asociados a la supuesta coracha, también apuntan al mismo periodo y presentan materiales parecidos.

Adosado al muro que hemos identificado con la coracha, hemos documentando un pavimento construido con lajas de arenisca de La Malahá. Se conserva parcialmente, al encontrarse cortado por una gran fosa en la que se localizan piedras de grandes dimensiones. No hemos podido determinar con precisión su funcionalidad, pero por su aspecto parece tratarse de un pavimento perteneciente a una estancia que estuvo situada al exterior, probablemente perteneció a un patio o a una calle (Fig. 4). Esta segunda hipótesis puede venir reforzada por la existencia de diversas canalizaciones que discurren por debajo y que describiremos más adelante.

Estas piedras de gran tamaño pueden pertenecer a derrumbes del muro o deberse a una colmatación intencionada de este espacio como parece ser se hizo en el solar del Maristán para colmatar la coracha y construir encima.

Sobre el pavimento descrito y adosado al muro de la coracha se levanta un muro que discurre en dirección oeste-este (Figs. 4 y 6). Presenta una anchura de $60 \mathrm{~cm}$, una altura máxima 
conservada de $75 \mathrm{~cm}$ y $15 \mathrm{~cm}$ de mínima. Está construido con lajas de arenisca de La Malahá, trabadas con mortero rico en cal. Solo presenta cara en su lado norte, la ausencia de cara en su lado sur induce a pensar que estuvo adosado a otra estructura constructiva que no se ha conservado actualmente. Se encuentra cortado parcialmente por la cimentación de una tinaja de almacenamiento de agua de grandes dimensiones. Aunque no tenemos datos para interpretar su función, su adosamiento al muro de la coracha induce a pensar que formó parte de este entramado defensivo. Debajo del pavimento descrito apareció un nivel de grandes piedras, que parece formar parte de un relleno constructivo, aunque no hemos podido determinar su funcionalidad.

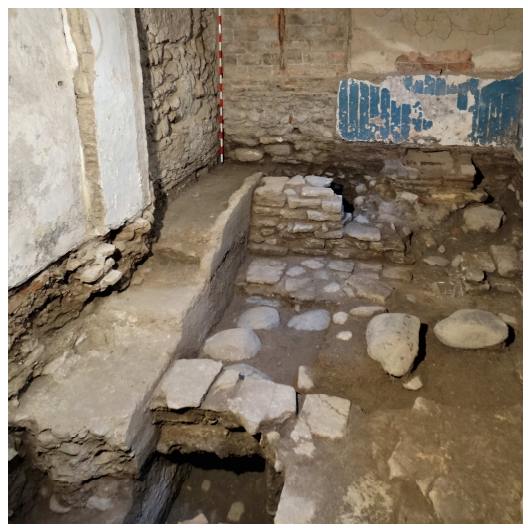

Fig. 4. Estructuras adosadas al muro de la coracha.

Tanto el pavimento como el muro que aparecen adosados al muro que hemos identificado con la coracha presentan unos materiales y técnicas constructivas muy similares a los utilizados en la construcción de la Bāb al-Difāf.

El muro de la coracha presenta dos roturas realizadas con la intencionalidad de evacuar las aguas sucias del Maristán por este punto. La más reciente está realizada rompiendo la última caja del tapial y a su vez rompe también el muro del Maristán. Aunque se observan restos de la circulación continua del agua sobre el tapial, no sabemos si hubo una atarjea construida encima, pues esta rotura, que parece realizarse durante la época cristiana, fue cegada posteriormente con tierra y piedras. El agua sucia venía a desembocar en una red una canalización situada a una cota inferior y de mayor antigüedad (Figs. 4, 5).

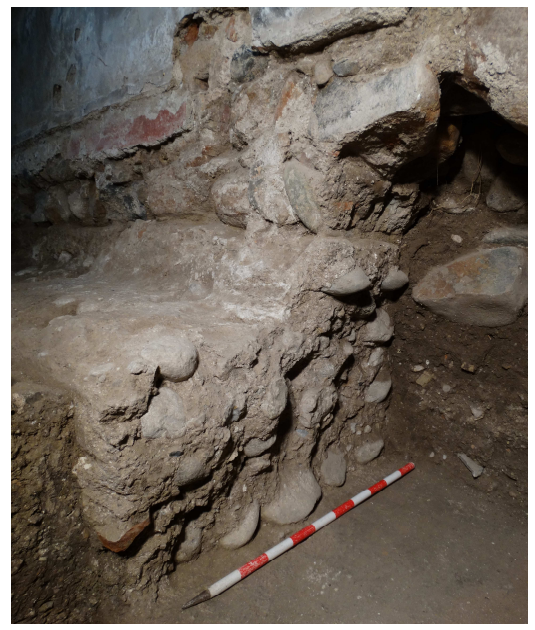

Fig. 5. Rotura de la muralla identificada como la coracha.

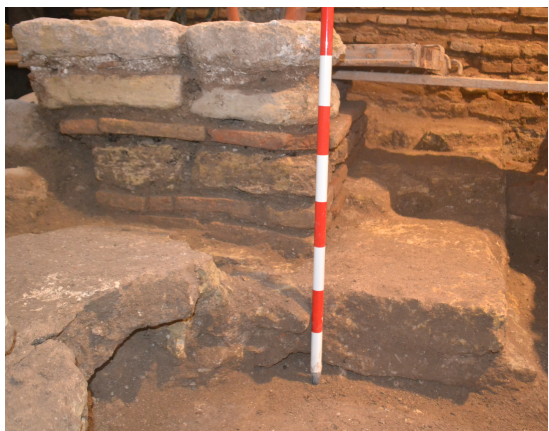

Fig. 6. Detalle de la fábrica del muro adosado a la muralla (C/ Concepción de Zafra) identificada con la coracha.

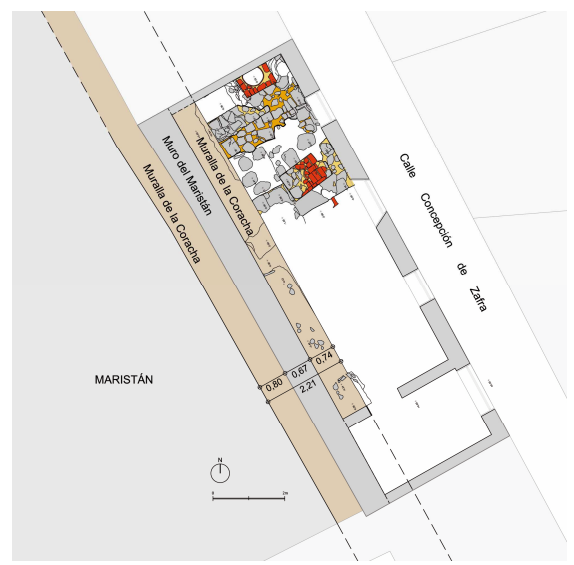

Fig. 7. Planta de la intervención arqueológica. Dibujo realizado por Marta Rivero y Víctor Martín. 


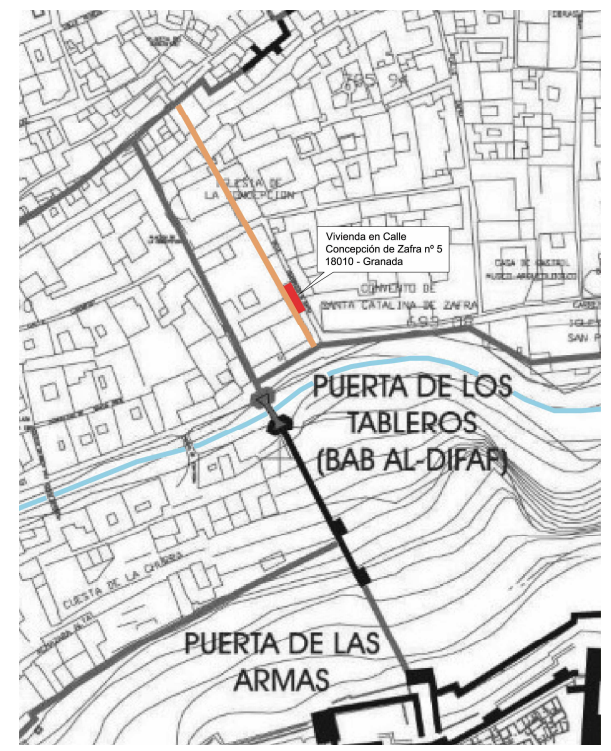

Fig. 8. Propuesta tradicional del trazado de la coracha (color gris) y nueva hipótesis (color naranja). Dibujo realizado por Víctor Martín sobre plano de Antonio Orihuela Uzal.

La segunda canalización o atarjea se origina en el Maristán, en un trazado que presenta una longitud documentada de $2,10 \mathrm{~m}$, rompe el muro de la coracha y gira hacia el sur, discurriendo paralela al exterior del citado muro. Justo en el quiebro el canal arranca con una anchura de $35 \mathrm{~cm}$ agrandándose hasta el siguiente quiebro hasta los $75 \mathrm{~cm}$, presenta una altura mínima de $60 \mathrm{~cm}$, aunque no sabemos la altura total dado que solo lo hemos excavado parcialmente. En el último quiebro que hace esta canalización gira en dirección este y presenta una cubierta de grandes lajas de piedra arenisca de La Malahá con un grosor variable de entre 20 y $40 \mathrm{~cm}$. El canal presenta una longitud de $2,70 \mathrm{~m}$, una anchura de $85 \mathrm{~cm}$ y una altura de $80 \mathrm{~cm}$. Al no poder documentar en detalle la red de canalizaciones debido a los límites que impone la arqueología urbana, supeditada al proyecto de obra, no podemos asegurar que se trate de una canalización del Maristán o anterior a este edificio o incluso una perforación coetánea a la propia coracha para el desagüe de aguas en este punto (Figs. 4, 5).

\section{Conclusiones}

La estructura de mayor interés aparecida, es decir, el muro de tapial localizado bajo el muro del Maristán y que también fue localizado en las excavaciones llevadas a cabo en el hospital nazarí en la campaña de 1985 (Salvatierra, García, 1987a, p. 449), era un muro sobre el que se asentaban los cimientos de fundación del Maristán (Fig. 3). Hemos intentado ver esta estructura en el solar del Maristán, aunque no ha sido posible ya que el sondeo en el que fue documentado se encuentra cerrado actualmente.

Por otro lado, si hemos podido ver la procedencia de la canalización que pasa por debajo del muro de la coracha atravesándolo, y que se localiza bajo la alberca del Maristán a la que hemos accedido a través de un pozo que se perforó en ella. La atarjea es posterior al muro pues lo rompe para pasar al otro lado utilizando su pared para realizar su recorrido hacia el río Darro. Adosadas al muro de la coracha localizamos una serie de estructuras coetáneas sobre las que destacan especialmente unas cubiertas de lajas de la Malahá pertenecientes a dos canalizaciones. La red de atarjeas de gran capacidad que encontramos en este pequeño solar puede indicar que estamos en una calle o espacio abierto.

Para el estudio de estas estructuras nos basamos en nuestra intervención (Fig. 7) y en los resultados de las intervenciones arqueológicas llevadas a cabo en el Hospital Nazarí al compartir ambos inmuebles las estructuras aparecidas (Fig. 3). Según García Granados y Salvatierra, este muro pertenecía a la coracha sobre la que se situarían casi exactamente los muros perimetrales este (que es el que estudiamos) y oeste del Maristán (García Granados, et all., 1989, p. 25).

Siguiendo la hipótesis de los citados arqueólogos, la posible coracha estaría formada por dos muros paralelos, de más de $2 \mathrm{~m}$ de grosor cada uno, definiendo un amplio pasillo de unos $26 \mathrm{~m}$ que permitía subir el agua desde el río a la alcazaba antigua mediante carros o caballerías (García Granados, et all., 1989, pp. 22-24). El muro oriental podría ser el que hemos identificado en la intervención arqueológica que nos 
ocupa, pues las medidas que presenta, una altura mínima de $2 \mathrm{~m}$ y una anchura de $1,10 \mathrm{~m}$ (a lo que tendríamos que sumar la parte que queda al otro lado del Maristán), apuntan a una construcción de tal entidad.

Solo los estudios arqueológicos en el resto de las viviendas de esta calle, en el Monasterio de la Concepción y en el propio Maristán confirmarán o desmentirán esta hipótesis (Fig. 8). Las realizadas hasta el momento en el hospital nazarí tan solo han documentado una serie de edificios de difícil interpretación por el impacto que sobre ellos produjeron las distintas edifica- ciones, en especial la alberca, pero no han aparecido resultados concluyentes acerca de la coracha.

El lienzo de tapial localizado en nuestra intervención se situaría cronológicamente en torno el siglo XI, y estaría, por tanto, en concordancia con el material cerámico recuperado (decoraciones en cuerda seca y melado y manganeso, cerámica de cocina sin vidriar), datada entre los siglos XI-XII, así como por la técnica constructiva, tapial de cal y canto, similar a otras edificaciones correspondientes a esta fecha localizadas en su entorno.

\section{Bibliography}

Adroher Auroux, A.M.; Pachón Romero, J.A. (2002). La Cultura Ibérica: Granada Arqueológica, Granada.

Bermúdez Pareja, J. (1966). “Un trozo de la cerca de Granada recuperado”, Cuadernos de la Alhambra, 2, pp. 139-140.

Bramon, D. (1991). El mundo en el siglo XII. Estudio de la versión castellana y del "Original” árabe de una geografía universal: "El tratado de al-Zuhrī”, Barcelona.

García Gómez, E.; Leví-Provençal, E. (1981). El siglo XI en $1^{a}$ persona. Las "Memorias” del 'Abd Allāh, último rey zirí de Granada, destronado por los Almorávides (1090), Alianza Editorial, Madrid.

García Granados, J.A.; Girón Irueste, F.; Salvatierra Cuenca, V. (1989). El Maristán de Granada. Un hospital islámico, Asociación Española de Neuropsiquiatría/Asociación Mundial de Psiquiatría Ed., Granada, p. 106.

García Granados, J.A. (1996). "La primera cerca medieval de Granada. Análisis historiográfico", Arqueología y Territorio Medieval, 3, pp. 91-147.

Gómez-Moreno González, M. (1892). Guía de Granada, 2 vols., Edición facsímil (1982), Granada.

Gómez-Moreno, M. (1905). "De Iliberri a Granada”, Boletín de la Real Academia de la Historia, 46, pp. 44-61.

López Jiménez, J. (2013). "Las corachas en al-Andalus. Las corachas-minas en la frontera nazarí occidental”, Takurunna: Anuario de Estudios sobre Ronda y La Serranía, 3, pp. 71-90.

López López, M. (2001). Excavaciones arqueológicas en el Albaicín, Granada. II. Plaza de Santa Isabel la Real, Agencia Albaicín, Granada.

Martín García, M.; García Granados, J.A. (1983). El Maristán de Granada. Situación, historia y descripción, Los Papeles del Carro de San Pedro, Granada.

Orihuela Uzal, A. (2002). Plano de Granada Árabe (Luis Seco de Lucena), Edición facsímil, Estudio preliminar.

Salvatierra Cuenca, V.; García Granados, J.A. (1987a). "Segunda Campaña de Excavación en el Maristán de Granada. Campaña de 1985", Anuario Arqueológico de Andalucía, pp. 447-452.

Salvatierra Cuenca, V.; García Granados, J.A. (1987b). "Tercera Campaña de Excavación en el Maristán de Granada. Campaña de 1987”, Anuario Arqueológico de Andalucía, pp. 367-370.

Sarr Marroco, B. (2007). "La Granada Zirí: una aproximación a través de las fuentes escritas, arqueológicas e historiográficas”, Arqueología y Territorio, 4, pp. 165-180.

Sarr Marroco, B. (2011). La Granada Zirí (1013-1090), Granada.

Seco de Lucena Escalada, L. (1910). Plano de la Granada árabe.

Seco de Lucena Paredes, L. (1968). “Acerca de la Qawraya de la Alcazaba Vieja de Granada”, Al-Andalus, 33, pp. $197-203$.

Seco de Lucena Paredes, L. (1975). La Granada nazarí del siglo XV, Patronato de la Alhambra, Granada.

Torres Balbás, L. (1940). "La Alhambra de Granada hasta el siglo XIII”, Al-Andalus, V, pp. 155-174.

Vílchez Vílchez, C. (2012) "La primitiva puerta de Hiṣn al-ḥamrā' en la etapa Zirí (s. XI)”. MEAH, Sección Árabeislam, 61, pp. 127-148. 